\title{
A brief Status analysis of the Quality of Secondary School Physical Education and Promotion Strategy
}

\author{
Fan Mingmei \\ Nanchangcityhealthschool 330006 492496227@qq.com
}

Keyword: secondary school; Physical Education; teaching quality;

\begin{abstract}
Physical education in China's educational system is as an important discipline, it plays an important role for building sports education system. Meanwhile, with the large-scale and standardization of secondary schools, the optimization of the teaching quality of secondary school physical education becomes particularly important. This paper on the basis of analyzing the status of the secondary school physical education quality, explores the strategy to improve the teaching quality of secondary school physical education that is to innovate physical education philosophy, improve infrastructure construction, and cultivate students' sports consciousness.
\end{abstract}

\section{Introduction}

Currently, with the attaching importance to physical education and continuous improvement of the physical education system, secondary school physical education occupies an increasingly important position in today's education system. As an important channel for training skilled personnel, secondary schools plays a promotion role for the rapid development of China's education. Meanwhile, with the improvement of people concerning about the health, physical education occupies an increasingly important role in education. As one of the important channels, secondary school shoulders important responsibilities and obligations. As a professional curriculum in secondary school, sports teaching plays an important role for enhancing students' sports consciousness and improving their physical fitness. As the state has invested heavily to secondary school, physical education has become a compulsory curriculum in secondary school, which laid a solid foundation for the training of professional talents [1]. In addition, physical education philosophy in secondary schools must adhere to student-centered. In physical education curriculum, it should give full play to the role of these professional courses to maximum exercise student initiative and creativity, and promote personality development of students. From recent years' development trend, the practical features of physical education are more and more significant, it is also the compulsory professional basis courses for training backbone teacher. From the reform of teaching methods to improve the countermeasures of teaching quality, physical education is gradually formed system.

With the rapid advances in information technology and the rapid economic and social development, it provides the motive force of development for physical education in secondary school. In the context of this development, the sports teaching activities are more and more active, the degree of integration of sports and sports science technology is gradually increased. Physical education curriculum presents the situation of the theoretical development, but also by the widespread concern in society. But it is undeniable that current physical education in secondary school still has many problems. For secondary schools, the training of personnel not only pay attention to the cultivation of professional ability, but also to strengthen physical exercise, so that professional competence and fitness are synchronous development. Seem from the development process of current secondary school physical education, the development of speed and pace of development of education in China is not completely synchronized, the specific practice teaching still has a number of issues, sports teaching has not yet achieved a certain practice height, the effect on the development of science and technology is not large. Thus, for the problem of the status quo of secondary school physical education, it must propose scientific strategy, to reform and innovate the physical education. 


\section{The status analysis of the quality of secondary school physical education}

\section{(1) Secondary school teaching methods lack of innovation}

In current secondary school physical education, the lagging of teaching methods impact on the quality of physical education in secondary schools to some extent. In the teaching content, some secondary school textbooks do not adapt to the pace of social development and timely update, many schools' sports materials have many disadvantages. in the traditional teaching materials setting, the set of sport items in general is too idealistic,

In general, assessment requirements dose not accord with the actual situation of students, the expectation for student is too high, and the level of practice exercises of physical activity is not high, so the rate of utilization of teaching resources is too low. In this state, the teaching methods in a lot of secondary schools do not to follow the way of teaching materials, sports materials are idle up [2]. Currently, the textbooks of secondary school mainly use the track and field events as the main teaching content, but the course content proportion of ball games, aerobics classes are small. At the most basic track and field events, professional settings from primary and middle school stage to the secondary vocational school stage, there is a single and mechanical characteristics. Meanwhile, in the teaching setting of extracurricular sports activities, the activities content is relatively simple. In physical education, due to the effects of the gold medal, it only concerned with some well-known majors, there has been one-sided teaching tendency, they too much emphasize on gold projects while ignoring some basic sports. In terms of teacher's resource allocation, it affected by enrollment system. The number of students relatively increase in a lot, in teaching which does not meet the needs of different students. In addition, because the unity of extracurricular physical education curriculum practice, exercise in secondary schools are more accordance with the wishes of the schools themselves, which is relatively traditional, has no advancing innovation, and cannot play a long time teaching effect.

(2) The lack of constructive infrastructure in secondary school

Physical Education is a strong practical discipline. For secondary schools, the sports infrastructure is material guarantee of the teaching quality in secondary schools. Seem from the current development trend, the infrastructure in secondary school mainly includes hardware and software facilities. Hardware facilities is a necessary condition for the development of the physical education in secondary school, and software facilities is the inherent power of the development of the physical education in secondary school [3]. In terms of hardware facilities, it mainly performs the inadequate sports facilities and equipment, less funding for physical education in secondary school, so there has been a lack of sports facilities and aging equipment. In this trend, it will seriously affect the quality of teaching, we can say, the hardware facilities are not in place to carry out a direct impact on physical education. The software of physical education in secondary school refers to that in order to adapt the teaching, it needs to make the concept innovation, facility teaching staff construction and teaching mode and so on. Currently, the sports software facilities of secondary school are in the lagging phase, which mainly shows for the more traditional teaching philosophy, lack of faculties, teaching mode needed to innovate, etc. through a few of these insufficient it can be found, imperfect software facilities for the quality of physical education in secondary schools have serious impediment. So, in physical education in secondary schools, hardware and software facilities is indispensable, the hardware facilities are basic security of software facilities, and software facilities are basic for hardware facilities, they both united in the sports teaching practice in secondary schools.

(3) Students in secondary school lack sport consciousness

In the traditional ideology, the physical education curriculum is a course of being marginalized, from primary education to secondary education and then to university education, sports programs are existed. in the teaching process of the physical education curriculum, the majority of students will see the physical education curriculum as a subsidiary subject, and most students are present passive adaptation state, it can be said, in such effects of long-term absence of sports consciousness, physical education in secondary school becomes somewhat difficult, after finding this phenomenon, many teachers presents a passive teaching phenomenon. Seem from the perspective of long-term 
development of physical education in secondary school, it needs to correct the lack of sports consciousness of students [4]. Meanwhile, after entering the secondary school, most students are more emphasis on professional courses, most students pay attention to the study of specialized courses, which many students will look physical education curriculum as the minor subject. In addition, due to the school is more focused on the assessment of professional courses for students' literacy training, it has led many students to ignore or even give physical education curriculum. In today's society, with the improvement of living standards, most students are only child, the grew up is relatively well-off, they did not have enough spirit to endure hardship, and the physical education teaching in secondary school requires a certain exercise load, which resulted in boredom for some students in sports course, we can say that this affects the process of physical education to a large extent. Therefore, from the ideology of students it can be seen, whether the student has the motivation for physical education will directly affect the physical education quality in secondary school.

\section{The strategy of to enhance the teaching quality of secondary school physical education}

\section{(1) Philosophy innovation of physical education}

For the hysteresis characteristics of teaching model that exist in secondary school physical education, in order to better improve the quality of physical education in secondary schools, the first is to innovate the physical education method in secondary school. Secondary schools should pay attention to physical education, adhere to enhance students' physical fitness as a starting point, enable students to strengthen the training activities in sports, establish the teaching philosophy that exercise and knowledge are equally important. In physical education, it should focus on the characteristics of students' subjectivity; in courses selection, it should focus on the updates and practicability of physical education materials; in the curriculum setting, it should reflect the flexibility to positively adapt to the trend of social and educational development. The traditional teaching concept is need to abandon and carry forward, abandoning the traditional teaching philosophy of teacher or classroom-centered, promoting the student-centered teaching model, to form of a school supervision, teacher guides and student practice system. Meanwhile, it should focus on improving sports concepts, transform the teaching objective from the traditional assessment to cooperative, to play students' sports spirit in an optimum interaction. Physical education reform in secondary school is a long process, the philosophy innovation of physical education is a gradual process, but it is undeniable that with the idea innovation for the physical education in secondary school, quality of physical education in secondary school will be significantly improved.

(2) To improve infrastructure construction

In terms of the quality improvement of secondary school physical education, to improve the infrastructure is one of an important project, and to improve the infrastructure, but also to seize the construction of two major aspects, namely hardware and software facilities. On the one hand, in terms of hardware facilities, secondary schools can use technical means for physical education. Although physical education is more emphasis on the teaching applied to practice, to learn the theory of sport is essential, so the use of advanced multimedia technology in secondary school teaching is necessary. Through multimedia sport teaching methods, students will have a more profound understanding of physical education curriculum, and this intuitive and innovative teaching method has greatly attracted the attention of students in order to foster students' sports interest. Through the intuitive of multimedia technology, physical education transformed from a dull book to three-dimensional environment, it will undoubtedly promote the development of physical education in secondary school through this teaching facilities setting of physical education. On the other hand, in terms of software facilities, it needs to innovative student evaluation mechanism, make more emphasis on the learning process in physical examination, and focus on the objectivity of physical examination, the result of the student is not simply as the final grade, but is to encourage student's initiative as the ultimate goal. It can be said, as China's emphasis on education for secondary school physical education, the innovative physical examination methods for students are adapted to the 
development trend of physical education. Therefore, in the context of this development, it would require a comprehensive evaluation of the student's ability, a variety of assessment methods such as the combination of objective and subjective evaluation and so on are used to build students' assessment mechanism.

(3) Cultivation of students' sports consciousness

Ideology influences people's behavior and activities. In process of physical education in secondary schools, to cultivate students' sports consciousness and give full play to the initiative of the students is an important factor affecting the quality of physical education in secondary school. In cultivating students' sports consciousness, the school should actively guide students to pay the attention to the sports curriculum, and make innovative reform for PE curriculum, so as to maximum create a good sports teaching environment. For teachers, they should actively guide students' interest, to focus on transforming their role, breaking from the traditional way of teaching is not only a simple knowledge transfer, more importantly, is to bring up the students interest in sports disciplines. Through the guide, so that students are willing to learn, active learning, teachers guide students' interest. At the same time, teachers should establish mechanisms for interaction learning with students, regularly set certain learning program for students, to give maximum help in the completion of the planning process, which eventually formed the habit of exercise. For the current status of China's secondary school physical education, to develop students 'sports consciousness also need to focus on rendering the classroom atmosphere to attract students' attention. It can be said, to enhance students' sports consciousness can promote the quality of physical education in secondary school.

\section{References}

[1]Liu Chengxiang, Liu Lin. The deficiency and construction of the interactive communication in college physical education [J]. China Adult Education, 2014(01).

[2]Wang Shuai. Exploration of the college Physical education reform [J]. Education Exploration, 2014(03).

[3]Li Wulei. The feasibility study of introduction of the outward training to physical education [J]. Education Exploration, 2013(09).

[4]Li Fengmei. The logic flaws and research inefficiencies of "Effective Physical Education" - the reflections based on the status of effective physical education [J]. Journal of Beijing Sports University, 2013(11). 